Research Article

\title{
The Impact of Arid Climate on the Indoor Thermal Comfort in the South-East of Morocco
}

\author{
Lamya Lairgi $\mathbb{D}^{1},{ }^{1}$ Rachid Lagtayi, ${ }^{2}$ Abdelmajid Daya, ${ }^{1}$ Rabie Elotmani, ${ }^{3}$ \\ and Mohammed Touzani ${ }^{1}$ \\ ${ }^{1}$ Department of Physics, Laboratory M3ER, FSTE, Moulay Ismail University, Meknes, Errachidia 509, Morocco \\ ${ }^{2}$ Department of Sciences, Industrial and Civil Technologies, Team of Sciences and Advanced Technologies, National School of \\ Applied Sciences, Abdelmalek Essaadi University, Tetouan 2121, Morocco \\ ${ }^{3}$ Sciences for Energy Laboratory LabSIPE, ENSAJ, Chouaib Doukkali University, El Jadida 1166, Morocco
}

Correspondence should be addressed to Lamya Lairgi; 1.lairgi@edu.umi.ac.ma

Received 15 February 2021; Revised 3 July 2021; Accepted 10 August 2021; Published 23 August 2021

Academic Editor: Mohammad Alghoul

Copyright (c) 2021 Lamya Lairgi et al. This is an open access article distributed under the Creative Commons Attribution License, which permits unrestricted use, distribution, and reproduction in any medium, provided the original work is properly cited.

The main objective of this work is to study the heat transfer through an administrative building's envelope in Errachidia City in Morocco. A numerical simulation based on the finite element method was made to describe the effect of introducing several thermal insulators (air, hemp wool, glass wool, rock wool, and extruded polystyrene) of different thicknesses $(5 \mathrm{~cm}, 10 \mathrm{~cm}$, and $15 \mathrm{~cm}$ ) on the heat transfer through the building's envelope under different climatic conditions. For the stationary regime, the summer period was chosen on August $7^{\text {th }}, 2019$, at $17 \mathrm{~h}$, while the winter period was opted on January $1^{\text {st }}, 2020$, at $7 \mathrm{~h}$. Otherwise, for the transitional regime, the summer period was chosen from August $1^{\text {st }}$ to $8^{\text {th }}, 2019$, and the winter period from January first to $8^{\text {th }}, 2020$. The physical model analyzes the temperature variation at the different layers of the wall. It depends on the indoor temperature, the instantaneous climatic conditions of the outdoor air, solar radiations, and the thermal properties of the building's envelope. The results show that the air gap is a good thermal insulator; it acts as a damper of temperature and heat flux.

\section{Introduction}

The thermal comfort's guarantee inside the building and the reduction of energy needs require the implementation of walls combining various functions and characteristics (insulation, accumulation/restitution of solar gains). The building's envelope presents the seat of heat transfer; it is the physical interface between the external environment and the indoor air, which is desired to be maintained on a stable temperature range. Thus, to ensure a good level of comfort for the occupants, the heat stored in summer must be evacuated by an air conditioning system. While in winter, the heat loss must be compensated by a heating system which leads to waste a huge amount of energy in most buildings. Therefore, to guarantee the lowest energy consumption and the high quality of indoor comfort, it is essential to develop a high-performance envelope. For this reason, sev- eral studies have been done to enhance the thermal performance of a building's envelope such as using advanced materials [1-4], employing insulation layers [5-7], and varying its thickness [8].

In the literature, several researchers have focused on the impact of thermal insulations and its characteristics on the heat transfer through the building's envelope. Asan [9] presented a study about the influence of thermophysical characteristics of a building's wall on time lag and decrement factor taking into account the convection boundary conditions; he has proven by computations applied for different building materials that those characteristics have a significant impact on the time lag and decrement factor. Boukendil et al. [2] examined a 2-D steady-state model to study the coupled conductive, convective, and radiative heat transfer through a honeycomb wall with a medium of air gap. The results show that the total heat flux through this wall varies almost 
TABLE 1: Thermophysical characteristics of opaque walls.

\begin{tabular}{|c|c|c|c|c|c|}
\hline & Wall composition & $\lambda(\mathrm{W} / \mathrm{m} \cdot \mathrm{K})$ & $\mathrm{Cp}(\mathrm{J} / \mathrm{kg} \cdot \mathrm{K})$ & $\rho\left(\mathrm{kg} / \mathrm{m}^{3}\right)$ & $e(\mathrm{~m})$ \\
\hline \multirow{5}{*}{ External walls } & Coating & 1.153 & 1000 & 1700 & 0.01 \\
\hline & Clay hollow brick & 0.915 & 790 & 720 & 0.15 \\
\hline & Air gap & 0.023 & 1004 & 1.3 & 0.05 \\
\hline & Clay hollow brick & 0.915 & 790 & 720 & 0.15 \\
\hline & Coating & 1.153 & 1000 & 1700 & 0.01 \\
\hline
\end{tabular}

linearly despite the difference between the indoor and the outdoors's temperature. They also concluded the overall heat exchange coefficients for the thermal behavior prediction of this wall system. In addition to this, other researchers proved that the use of air gap gives optimal results. Jamal et al. [10] studied the coupled heat transfer mode by conduction, natural convection, and radiation in a double solid wall with a medium of air gap. The result shows that the use of air gap as insulation would highly help in reducing the energy consumption of buildings.

This type of field's research is still topical in the whole globe [11-17] and also in Morocco [18-20]. The paper is aimed at analyzing the following:

(i) The effect of introducing five insulations (air, glass wool, hemp wool, rock wool, and extruded polystyrene) in a building's envelope on the heat transfer and the heat flux through this wall

(ii) The impact of insulation's thickness on the heat transfer and the heat flux through this envelope

(iii) The climatic conditions were determined during a summer week in August 2019 and a winter week in January 2020, while the used model is based on the finite element method

\section{Materials and Methods}

2.1. Model Description. The numerical model consists of solving the problem of heat transfer in stationary and transitional regimes, during a winter week between the $1^{\text {st }}$ and $8^{\text {th }}$ January 2020, and another summer week from the $1^{\text {st }}$ to $8^{\text {th }}$ August 2019, through the exterior walls of an administrative building (Pachalik Errachidia). The external walls under study are made of clay hollow brick with a thickness of $15 \mathrm{~cm}$ separated by a medium of air gap with a thickness of $5 \mathrm{~cm}$ (Table 1 ).

$\lambda$ is the thermal conductivity, Cp is the specific heat, $\rho$ is the density, and $e$ is the thickness.

The geometric configuration of a multilayer building's envelope is illustrated in Figure 1. The left side of the wall is exposed to the ambient air, while its temperature $T_{\mathrm{i}}$ is maintained constant. A convective heat transfer occurred between the interior facade and ambient air. The right facade of the wall is opened to a periodic outdoor ambient air temperature $T(t)$ and towards the solar radiations $\varphi(t)$. Convective and radiative conditions are established inside and outside the wall, and it is translated by global coefficients he and hi.

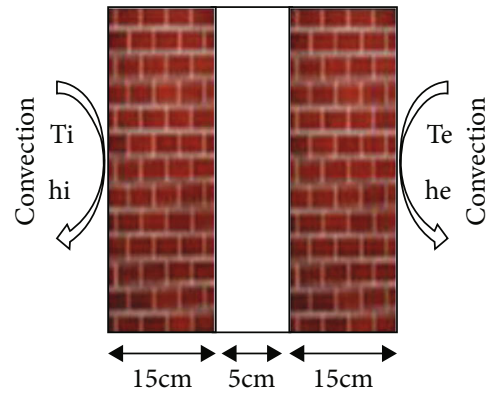

FIGURE 1: Building's external walls.

For the summer and winter periods with a wind speed $v<5 \mathrm{~m} / \mathrm{s}$, the convective heat transfer coefficients he [21] and hi [22] are given by

$$
\begin{aligned}
& h_{\mathrm{e}}=5.7+3.8 v, \\
& h_{\mathrm{i}}=2.03\left(\frac{\left|T_{\mathrm{air}}-T_{3 i}\right|}{2 H}\right)^{0.22},
\end{aligned}
$$

where $v$ is the average wind speed $\mathrm{m} / \mathrm{s}, T_{\text {air }}$ is the indoor ambient temperature, $T_{\text {si }}$ is the outdoor average temperature, and $H$ is the wall's height.

2.2. Method. The external wall under study is assumed to be only in the $x$ direction and time dependent. The one-dimensional, transient heat conduction equation for this problem is as follows:

$$
\lambda \frac{\partial^{2} T}{\partial x^{2}}=\rho \operatorname{Cp} \frac{\partial T}{\partial t}
$$

where $\lambda$ is the thermal conductivity, $\rho$ is the density, and $\mathrm{Cp}$ is the specific heat of the wall material.

2.3. Initial and Boundary Conditions. We have opted for the following boundary conditions:

(i) The thermophysical properties of the materials are assumed to be constant

(ii) The contact between the brick and the insulators is assumed to be perfect

(iii) The horizontal sides of the wall are adiabatic 
TABLE 2: Characteristic data of the studied wall.

\begin{tabular}{|c|c|c|c|c|}
\hline & $e(\mathrm{~m})$ & $H(\mathrm{~m})$ & $R_{\mathrm{si}}\left(\mathrm{m}^{2} \cdot \mathrm{K} / \mathrm{W}\right)$ & $R_{\mathrm{se}}\left(\mathrm{m}^{2} \cdot \mathrm{K} / \mathrm{W}\right)$ \\
\hline & 0.35 & 1 & 0.13 & 0.04 \\
\hline Period & \multicolumn{2}{|c|}{ Winter } & \multicolumn{2}{|c|}{ Summer } \\
\hline Stationary regime & $T_{\mathrm{i}}=20^{\circ} \mathrm{C}$ & $T_{\mathrm{e}}=0^{\circ} \mathrm{C}$ & $T_{\mathrm{i}}=25^{\circ} \mathrm{C}$ & $\mathrm{T}_{\mathrm{e}}=40^{\circ} \mathrm{C}$ \\
\hline Transitional regime & $T_{\mathrm{i}}=20^{\circ} \mathrm{C}$ & Figure 2 & $\mathrm{~T}_{\mathrm{i}}=25^{\circ} \mathrm{C}$ & Figure 3 \\
\hline
\end{tabular}

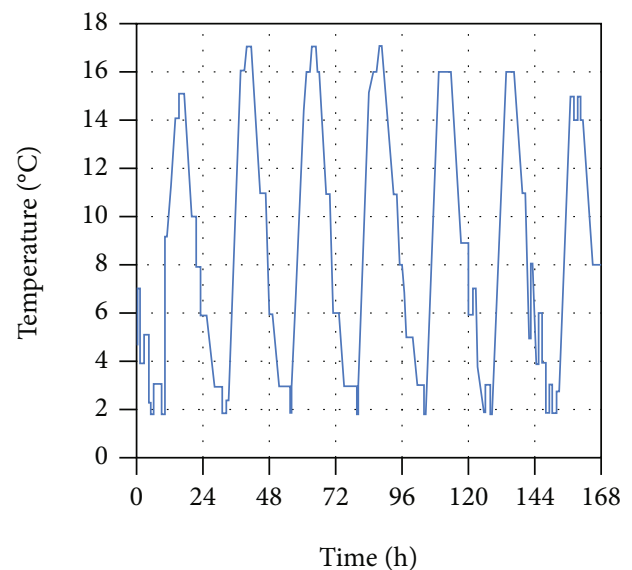

FIGURE 2: Outdoor temperature measured from January $1^{\text {st }}$ to $8^{\text {th }}$, 2020.

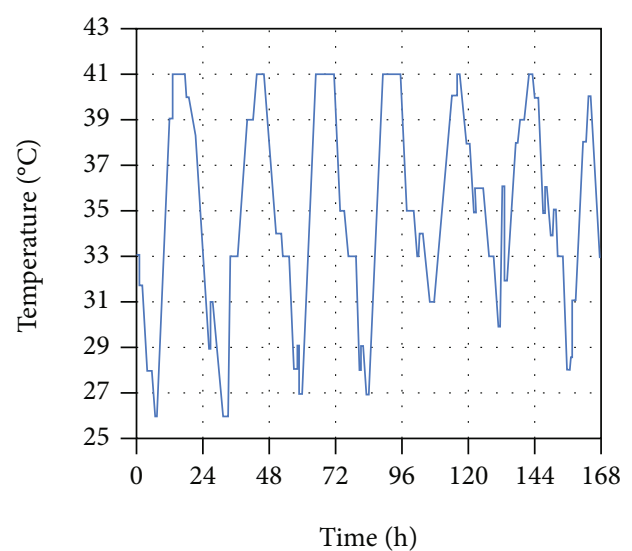

FIGURE 3: Outdoor temperature measured from August $1^{\text {st }}$ to $8^{\text {th }}$, 2019.

$$
\lambda \frac{\partial T}{\partial x}=0
$$

(iv) At the interior side of the wall, the boundary condition is

$$
\lambda \frac{\partial T}{\partial x}=h_{\mathrm{i}}\left(T_{x=0}-T_{\mathrm{i}}\right), \quad x=0,
$$

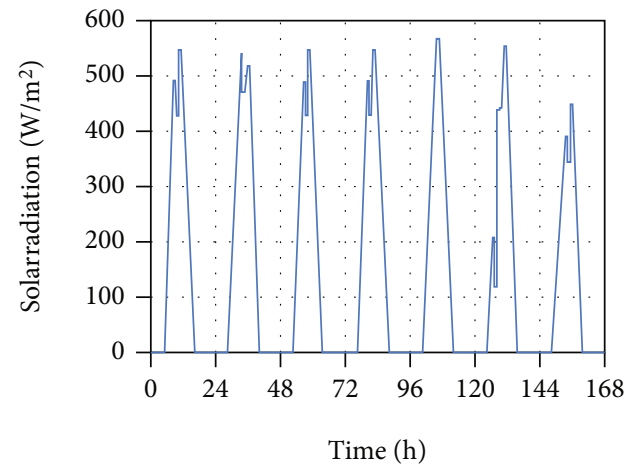

Figure 4: Solar radiations measured from January $1^{\text {st }}$ to $8^{\text {th }}, 2020$.

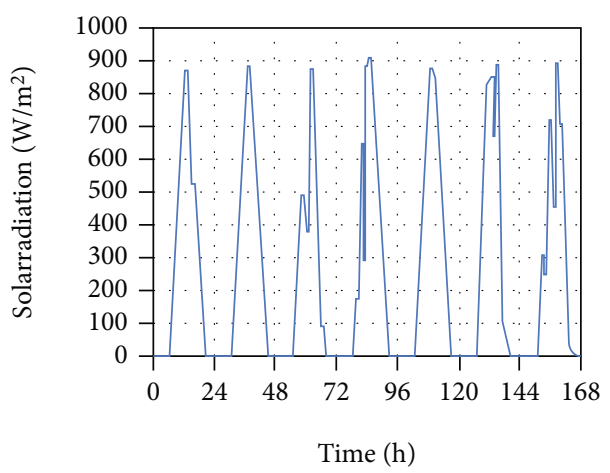

FIGURE 5: Solar radiations measured from August $1^{\text {st }}$ to $8^{\text {th }}, 2019$.

where hi is the interior convective heat transfer coefficients, $T_{x=0}$ is the wall interior side's temperature, and $T_{\mathrm{i}}$ is the indoor temperature

(v) At the exterior side of the wall, the boundary condition is

$$
\lambda \frac{\partial T}{\partial x}=h_{\mathrm{e}}\left(T_{\mathrm{e}}-T_{x=L}\right)+\alpha \varphi(t), \quad x=L
$$

where he is the exterior convective heat transfer coefficients, $T_{x=L}$ is the wall exterior side's temperature, $T_{\mathrm{e}}$ is the outdoor temperature, and $\varphi(t)$ is the solar radiation flux in which the solar absorption coefficient of the brick is $\alpha=0.6$ [23] 


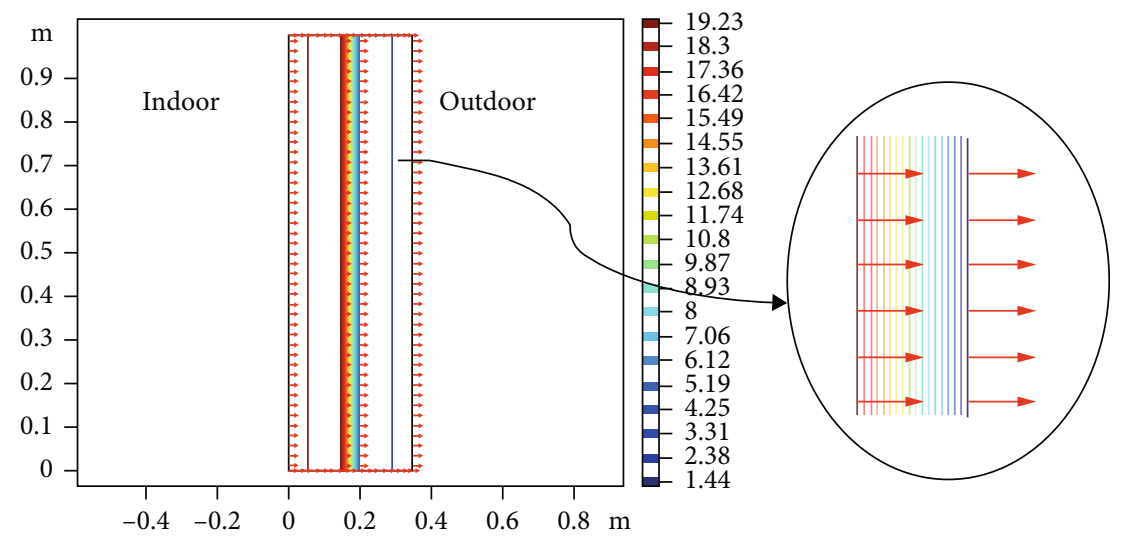

Figure 6: Total heat flux lines for the winter period.

(vi) Table 2 presents the characteristics of the studied wall (thickness $(e)$, length $(L)$, internal surface resistance $\left(R_{\mathrm{si}}\right)$, external surface resistance $\left(R_{\mathrm{se}}\right)$, and the initial conditions for stationary and transitional regimes during winter and summer periods

2.4. Climatic Data. The climate data conditions for the two studied periods (from $1^{\text {st }}$ to $8^{\text {th }}$ August 2019 and from $1^{\text {st }}$ to $8^{\text {th }}$ January 2020) were provided by Moulay Ali Cherif airport station. Indoors, the air temperature during the winter period is $20^{\circ} \mathrm{C}$, and during the summer period, it is $25^{\circ} \mathrm{C}$.

Figures 2 and 3 show the instantaneous measured values of the outdoor air temperature for the two periods. The climate of Errachidia City is semidesert, and it is characterized by a very hot summer season with a very high diurnal temperature range. Indeed, maximum temperatures reach $41^{\circ} \mathrm{C}$ during the day, with a diurnal amplitude of around $15^{\circ} \mathrm{C}$, and it is very cold in winter with minimum temperatures which can reach $0^{\circ} \mathrm{C}$. Solar radiation reaches up to $900 \mathrm{~W} / \mathrm{m}^{2}$ in summer and $500 \mathrm{~W} / \mathrm{m}^{2}$ in winter (Figures 4 and 5). These climatic conditions support the discomfort of the inhabitants.

\section{Results and Discussion}

\subsection{Stationary Regime}

3.1.1. Winter Period. The diagram shows the evolution of heat flux (Figure 6) at different points of the wall; it is a typical situation that occurs when the air temperature inside is warmer $20^{\circ} \mathrm{C}$ than the outdoor temperature $0^{\circ} \mathrm{C}$. Heat flux in the direction from the warm inside toward the colder outside portion of the wall. The inside of the building gets cold because of this, and a heater is needed to keep thermal comfort inside the building, which leads us to choose the appropriate thermal insulator to minimize the energy consumption of heating.

Figure 7 shows the temperature profiles at different thicknesses $(5 \mathrm{~cm}, 10 \mathrm{~cm}$, and $15 \mathrm{~cm})$ for different thermal insulations (air gap, glass wool, hemp wool, rock wool, and polystyrene) during the winter period. The profiles are similar and varied in the same manner for all thermal insulators.
We note that the increase of the insulators' thickness provokes an increase in the thermal resistance of the walls.

The impact of each thermal insulation for every chosen thickness is illustrated in Figure 8. We note that using air gap as an insulator reduces heat transfer through the studied wall with the three different thicknesses. The air gap blocks heat from exiting to the outside. The obtained results are similar to the results of Lairgi et al. [1].

3.1.2. Summer Period. Figure 9 shows the lines of the total heat flux at different points of the wall on August $5^{\text {th }}$, 2019 , at $14 \mathrm{~h}$. The inside ambient air's temperature equals $25^{\circ} \mathrm{C}$, which is colder than the outdoor temperature $\left(40^{\circ} \mathrm{C}\right)$. Consequently, the heat flux's direction is from the outside toward the inside portion of the wall. By observing the evolution of the heat flux (Figure 9) at any point of the wall, we note that the thermal insulation slows this heat transfer.

Figure 10 shows the temperature profiles for various thicknesses $(5 \mathrm{~cm}, 10 \mathrm{~cm}$, and $15 \mathrm{~cm})$ of different thermal insulators during the summer period. We note that the profiles are similar and vary in the same manner for all thermal insulations. Moreover, the increase of thermal insulators' thicknesses leads to a significant thermal resistance of the walls. These results are similar to the results obtained by Perumal et al. [24].

Figure 11 shows the effect of each thermal insulation for every chosen thickness during the summer period. We conclude that for the three thicknesses, thermal insulation by air gap is highly desirable; it gives the best results in terms of slowing heat transfer through the wall and reducing the costs.

3.2. Transitional Regime. According to the previous results, we have chosen a thickness of $5 \mathrm{~cm}$ of each thermal insulator for the transitional regime. To analyze the effect of different insulators on the heat transfer through the building's envelope, we have recorded the different temperatures, $T_{1}$ at the interior side, $T_{2}$ at the interior side of the insulator, $T_{3}$ at the exterior side of the insulator, and $T_{4}$ at the exterior side of the wall (Figure 12). 

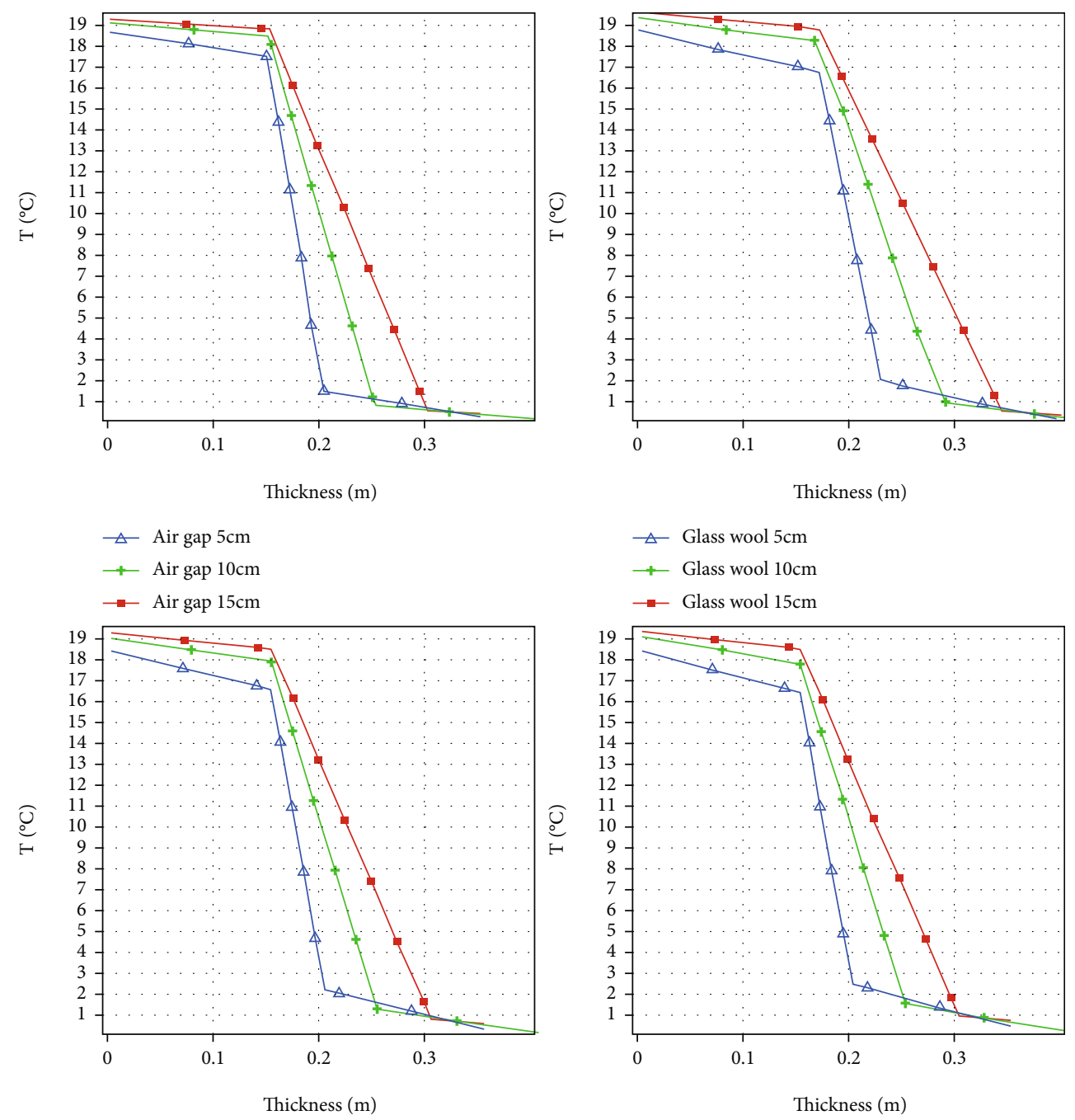

$\triangle$ Hemp wool $5 \mathrm{~cm}$
$\rightarrow-$ Hemp wool $10 \mathrm{~cm}$
$\rightarrow-$ Hemp wool $15 \mathrm{~cm}$

$\triangle$ Rock wool $5 \mathrm{~cm}$

+- Rock wool $10 \mathrm{~cm}$

$\rightarrow$ Rock wool $15 \mathrm{~cm}$

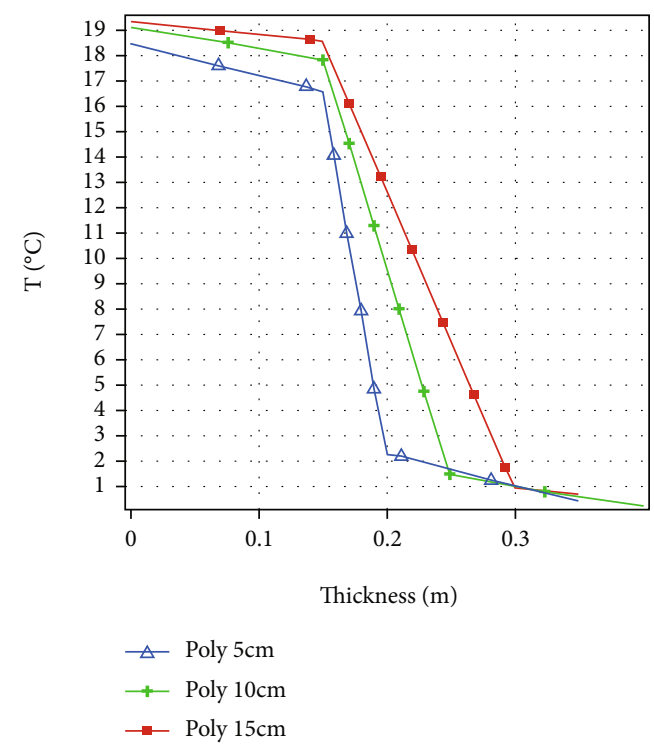

FIgURE 7: Temperature profiles at different thicknesses and thermal insulators during the winter period. 

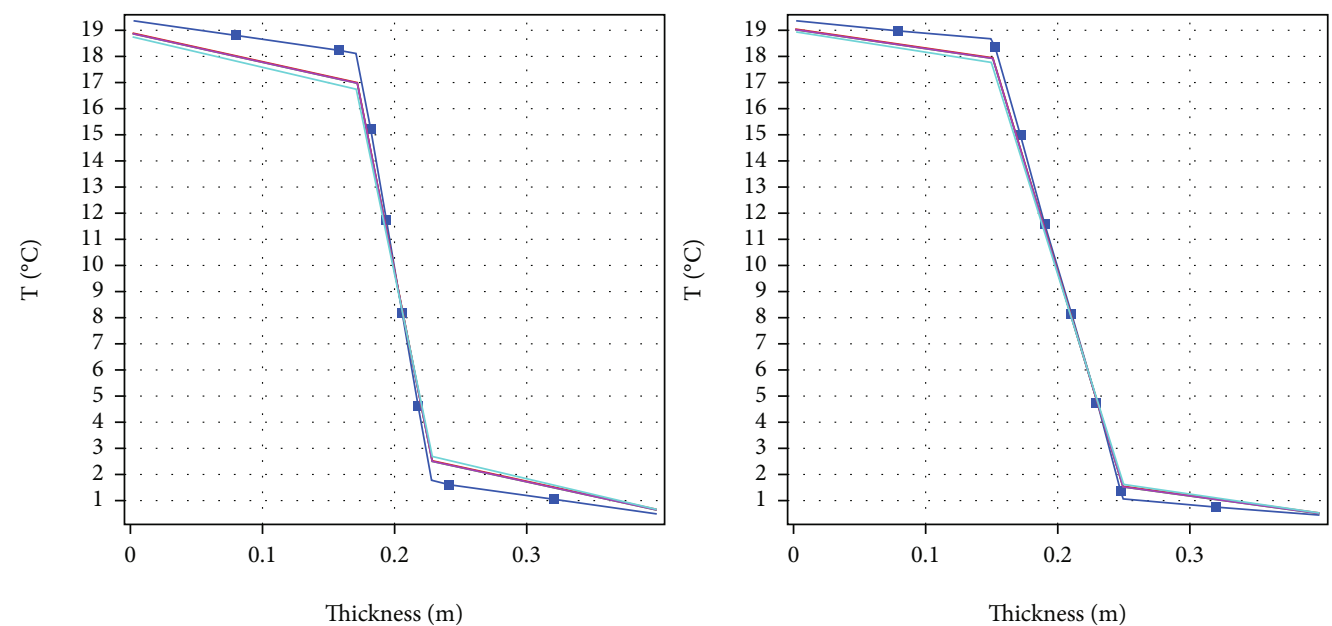

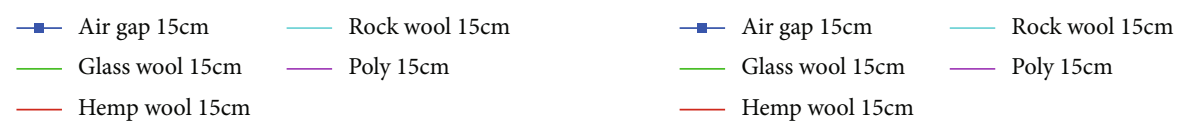

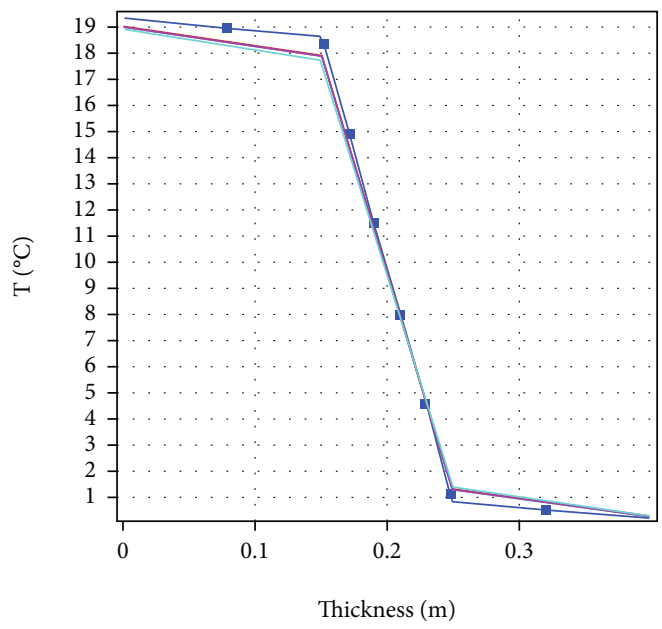

$$
\begin{array}{ll}
\longrightarrow \text { Air gap } 15 \mathrm{~cm} & \text { Rock wool } 15 \mathrm{~cm} \\
- \text { Glass wool } 15 \mathrm{~cm} & \text { Poly } 15 \mathrm{~cm} \\
- \text { Hemp wool } 15 \mathrm{~cm} &
\end{array}
$$

Figure 8: Temperature profiles for the three thicknesses and the different insulators during the winter period.

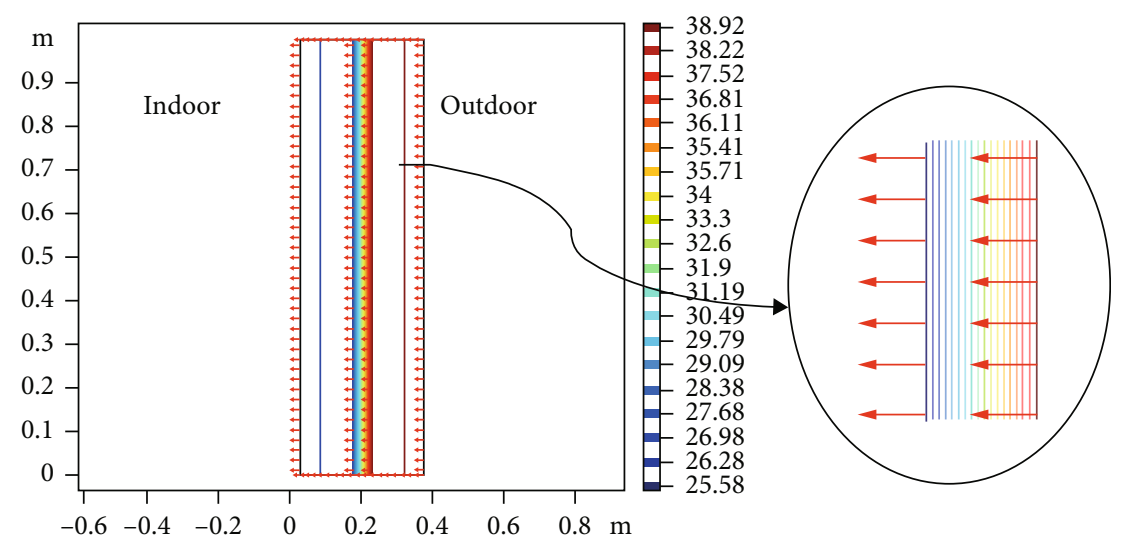

Figure 9: Lines of the total heat flux for the summer period. 

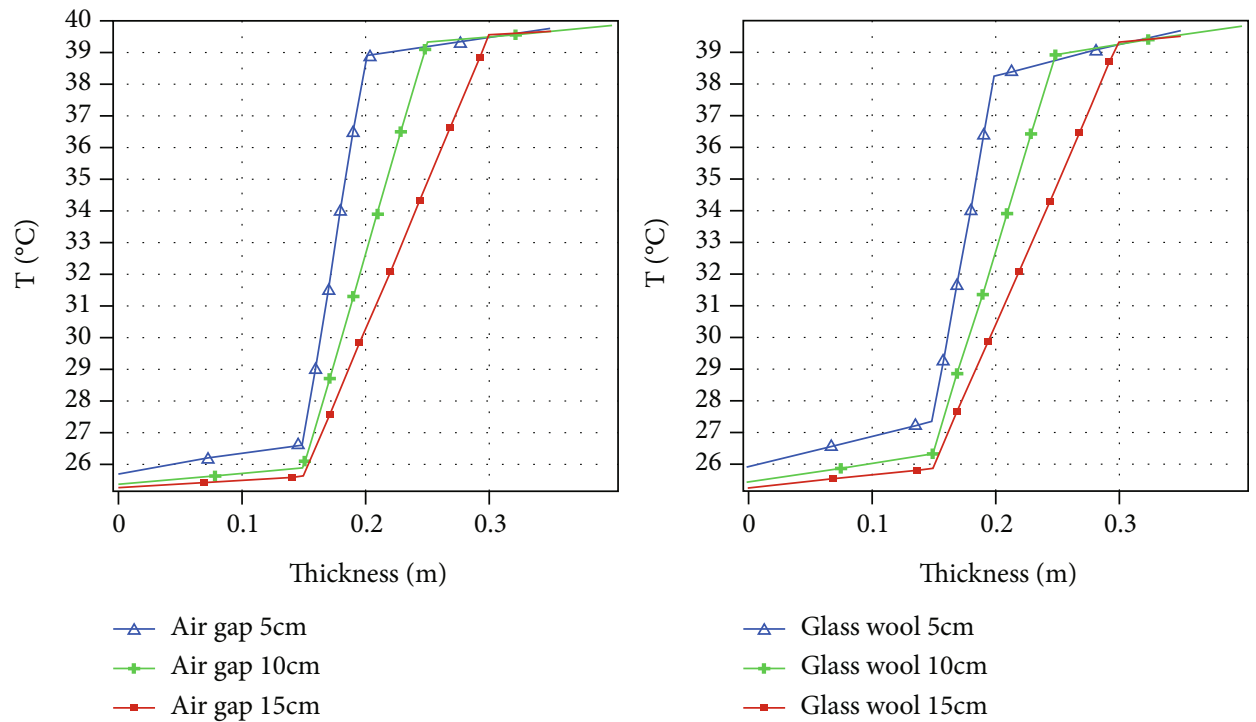

$$
\begin{aligned}
& \triangle \text { Glass wool } 5 \mathrm{~cm} \\
& - \text { Glass wool } 10 \mathrm{~cm} \\
& - \text { Glass wool } 15 \mathrm{~cm}
\end{aligned}
$$
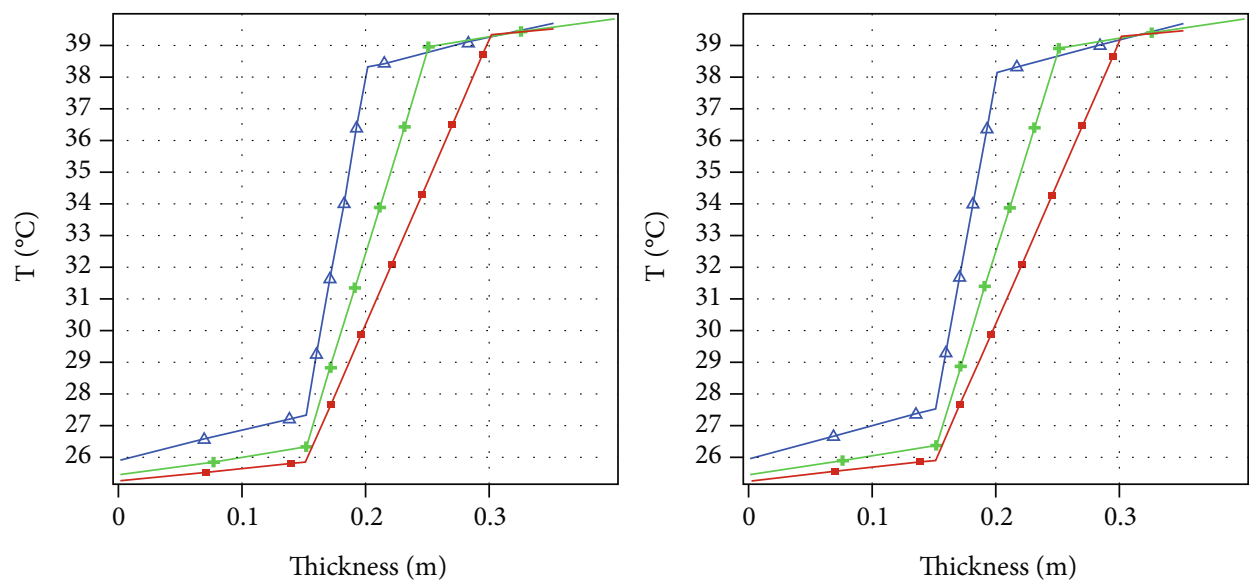

$$
\begin{array}{ll}
\triangle \text { Hemp wool } 5 \mathrm{~cm} & \rightarrow \text { Rock wool } 5 \mathrm{~cm} \\
\rightarrow-\text { Hemp wool } 10 \mathrm{~cm} & \rightarrow-\text { Rock wool } 10 \mathrm{~cm} \\
\triangle-\text { Hemp wool } 15 \mathrm{~cm} & \rightarrow \text { Rock wool } 15 \mathrm{~cm}
\end{array}
$$

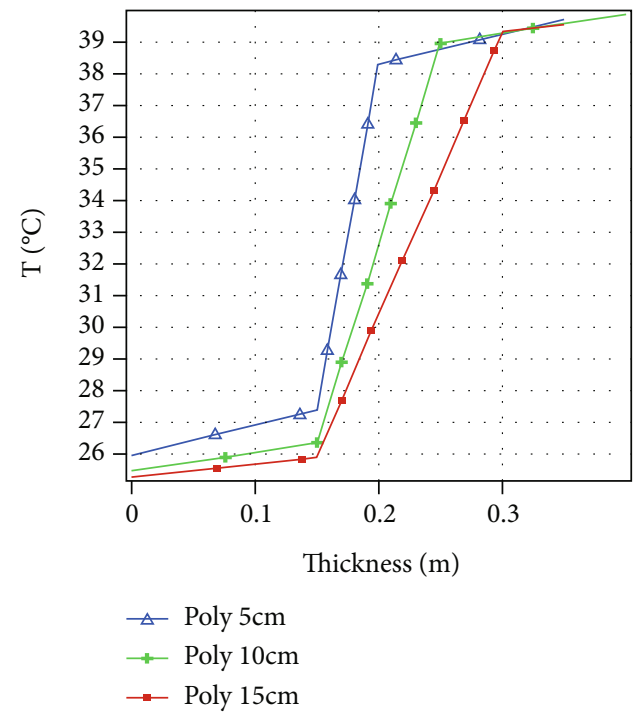

Figure 10: Temperature profiles for different thicknesses and thermal insulators during a summer period. 


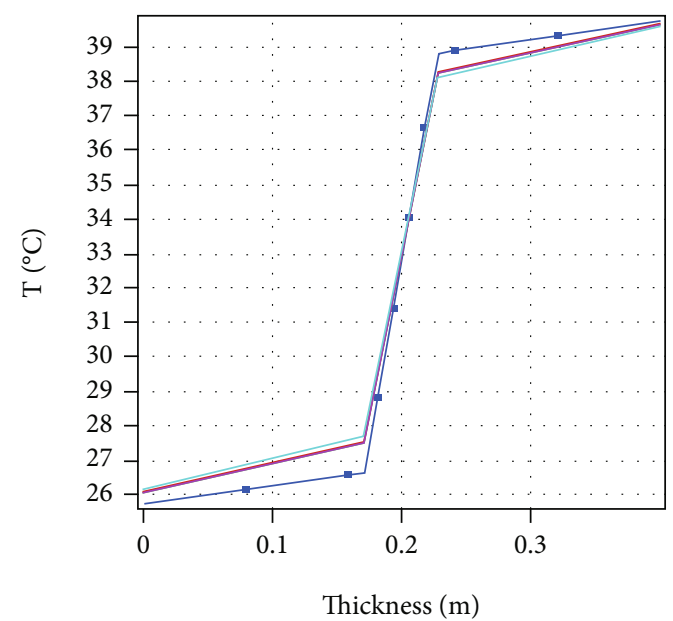

- Air gap $5 \mathrm{~cm} \quad$ Rock wool $5 \mathrm{~cm}$
- Glass wool $5 \mathrm{~cm}-$ Poly $5 \mathrm{~cm}$
- Hemp wool $5 \mathrm{~cm}$

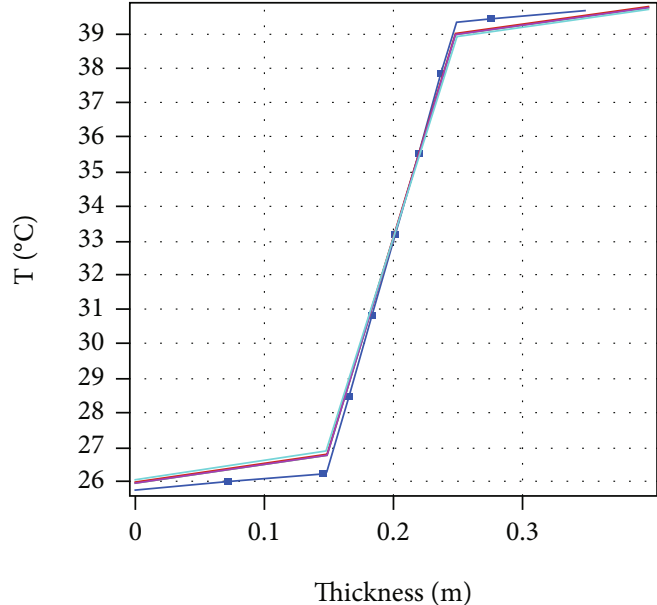

$=$ Air gap $10 \mathrm{~cm} \longrightarrow$ Rock wool $10 \mathrm{~cm}$

_ Glass wool $10 \mathrm{~cm}$ Poly $10 \mathrm{~cm}$

— Hemp wool $10 \mathrm{~cm}$

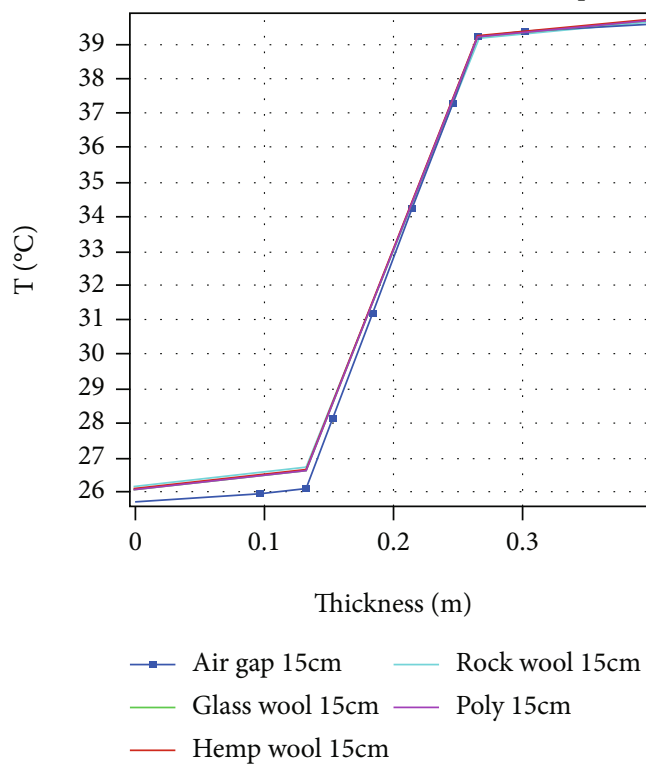

Figure 11: Temperature profiles for different thermal insulators with three thicknesses during a summer period.

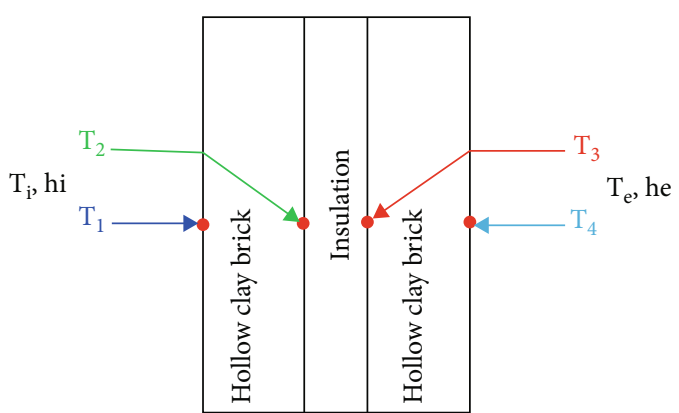

Figure 12: The schematic of the problem geometry.

3.2.1. Winter Period. Figure 13 presents the temperature's variation from January $1^{\text {st }}$ to $8^{\text {th }}, 2020$, at the midheight of the envelope, which is presented by a double-layered hollow clay brick and different thermal insulators (Figure 13).
The results show the layer's temperature waves in the same manner as the external side's one $T_{4}$. Moreover, we found that the temperature profile at the external facade of the wall $T_{4}$ and the external side of the insulation $T_{3}$ is almost identical, which reveals a high capacity of hollow clay bricks to store heat during the day and to diffuse it at night. The five insulations were studied acting as a thermal barrier that blocks heat to exit. Indeed, the temperature of the internal side of the insulation (glass wool, rock wool, hemp wool, and polystyrene) $T_{2}$ varies from a minimum of $18^{\circ} \mathrm{C}$ and a maximum of $19^{\circ} \mathrm{C}$ while its external side $T_{3}$ varies from $7^{\circ} \mathrm{C}$ to $18^{\circ} \mathrm{C}$ which disclose a heat block rate of $64 \%$. While for the air gap insulation, $T_{2}$ varies from $18.5^{\circ} \mathrm{C}$ to 19 and $\mathrm{T}_{3}$ waves from 6 to $19^{\circ} \mathrm{C}$ (Table 3). Thus, using air gap as insulation blocks heat to exit with a rate of $68 \%$. Consequently, the thermal insulation by air gap leads to an optimal result compared to the other thermal insulators under study. 

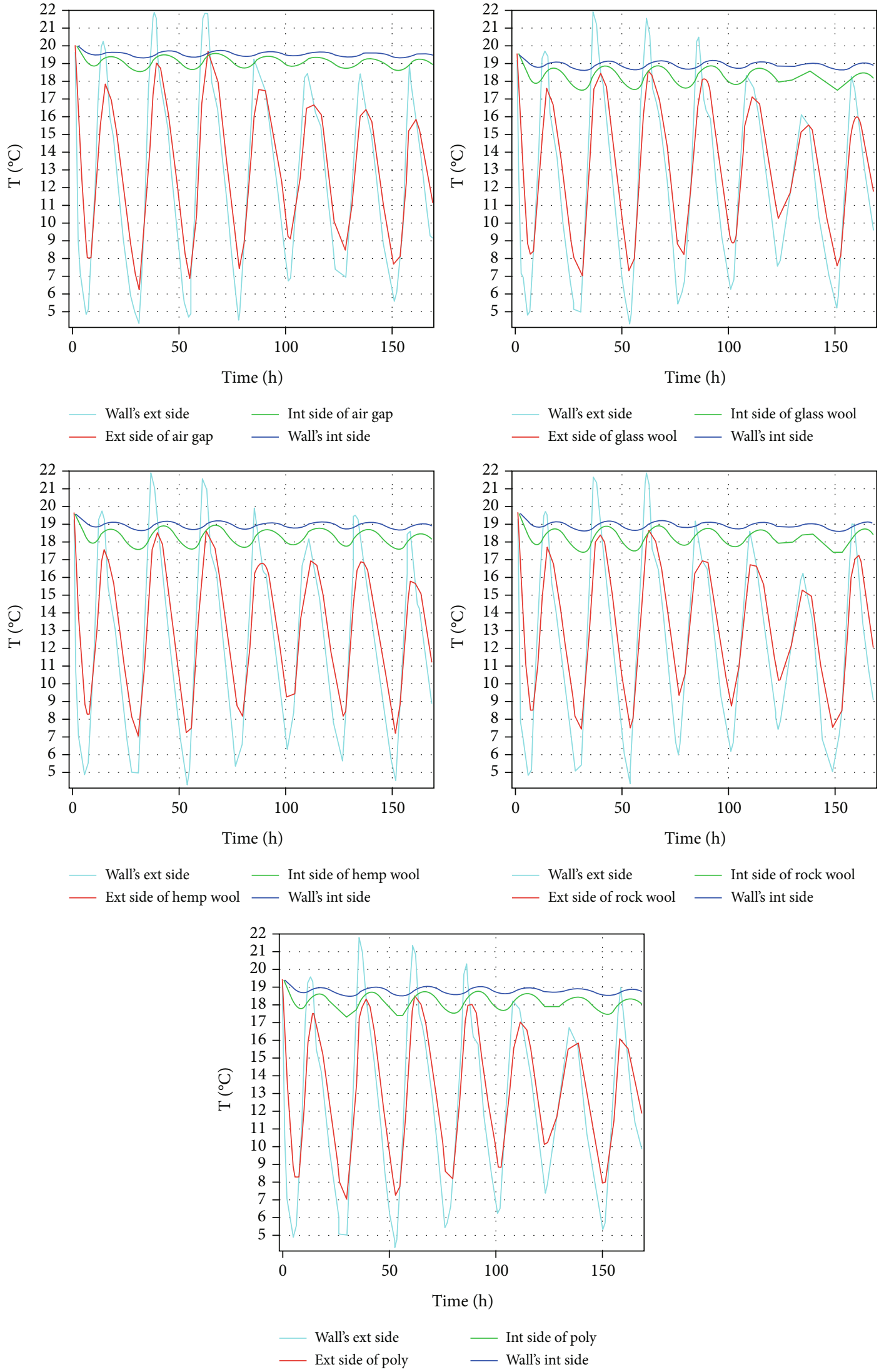

Figure 13: Temperature variation profiles on the building's envelope and thermal insulation during the winter period. 
TABLE 3: Side's temperatures for the five insulations in the winter period.

\begin{tabular}{|c|c|c|c|c|c|c|c|c|}
\hline \multirow[t]{3}{*}{ Insulators } & \multicolumn{8}{|c|}{ Temperature $\left({ }^{\circ} \mathrm{C}\right)$} \\
\hline & \multicolumn{2}{|c|}{$T_{1}$} & \multicolumn{2}{|c|}{$T_{2}$} & \multicolumn{2}{|c|}{$T_{3}$} & \multicolumn{2}{|c|}{$T_{4}$} \\
\hline & Min & Max & Min & $\operatorname{Max}$ & Min & $\operatorname{Max}$ & Min & $\operatorname{Max}$ \\
\hline Air gap & 19 & 20 & 18.5 & 19 & 6 & 19 & 0 & 18 \\
\hline Glass wool & 19 & 19.5 & 18 & 19 & 7 & 18 & 0 & 18 \\
\hline Hemp wool & 19 & 19.5 & 18 & 19 & 7 & 18 & 0 & 18 \\
\hline Rock wool & 19 & 19.5 & 18 & 19 & 7 & 18 & 0 & 18 \\
\hline Polystyrene & 19 & 19.5 & 18 & 19 & 7 & 18 & 0 & 18 \\
\hline
\end{tabular}
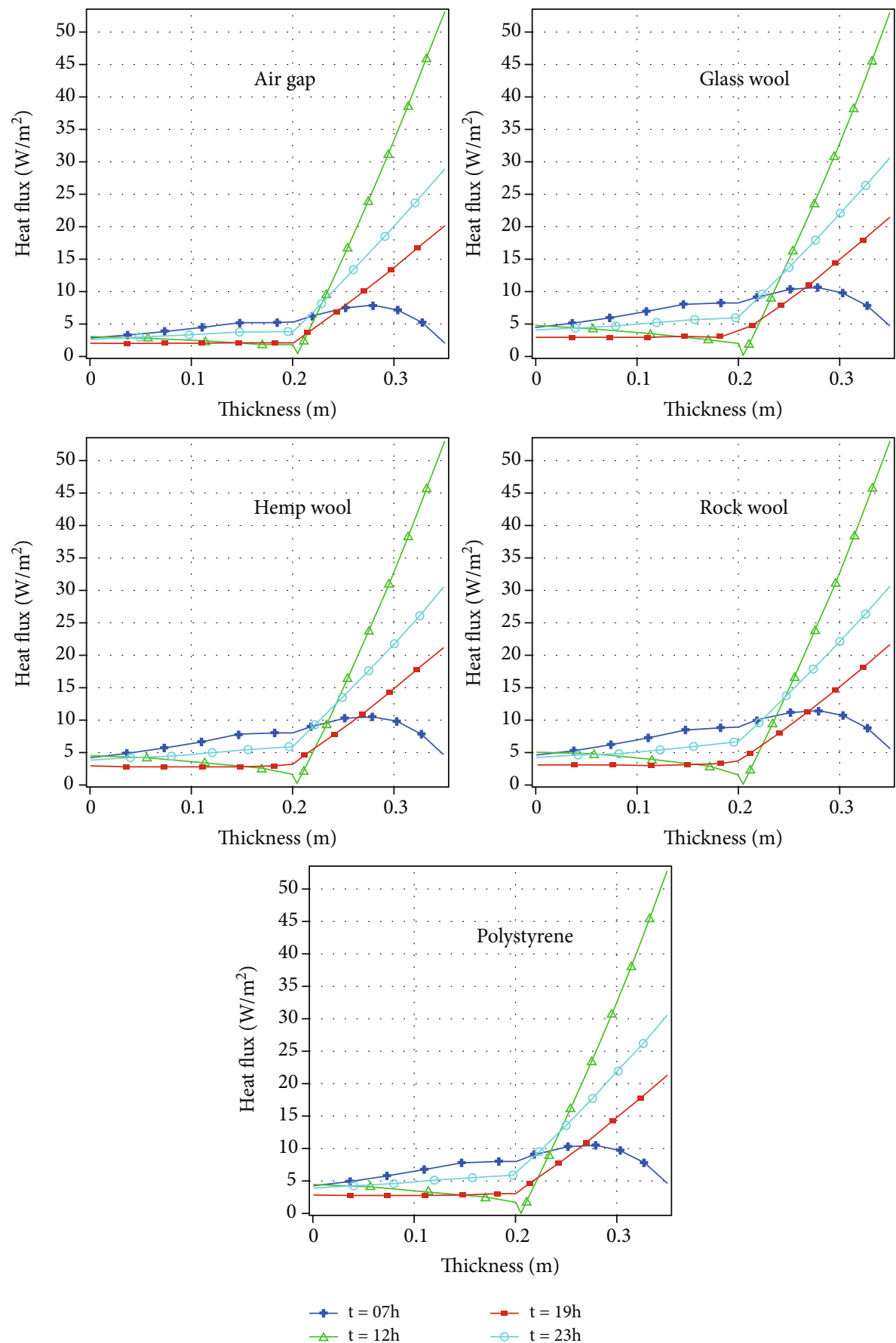

Figure 14: Heat flux as a function of the wall thickness and thermal insulator's types at different times of the day during a winter period. 


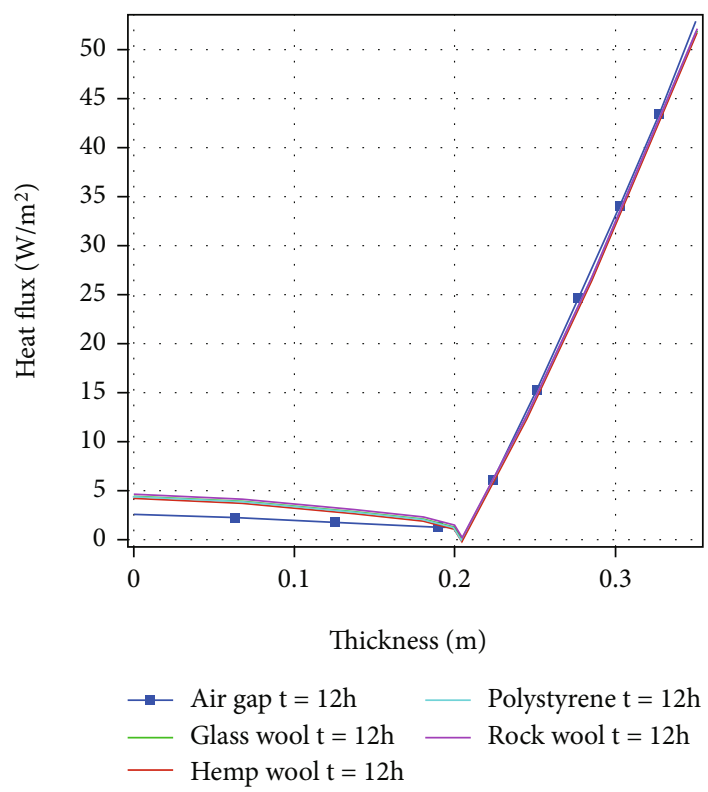

Figure 15: Heat flux as a function of wall thickness and thermal insulation's type at $t=12 \mathrm{~h}$ during a winter period.

These results have previously been highlighted by other recent researches $[1,6,10]$.

Figure 14 shows the heat flux as a function of the thickness four times per day ( $7 \mathrm{~h}, 12 \mathrm{~h}, 19 \mathrm{~h}$, and $23 \mathrm{~h}$ ) for the different insulators used.

The recorded flux for the five insulators (air gap, glass wool, hemp wool, rock wool, and polystyrene) is maximal at $12 \mathrm{~h}$ and minimal at $7 \mathrm{~h}$, and it varies approximatively from $20 \mathrm{~W} / \mathrm{m}^{2}$ to $30 \mathrm{~W} / \mathrm{m}^{2}$ between $19 \mathrm{~h}$ and $23 \mathrm{~h}$.

We note that the heat flux has a linear curve at the external layer of the wall, but with different values depending on the different moments during the day. At $12 \mathrm{~h}$, the heat flux is higher compared to another time, and it reaches a value of $55 \mathrm{~W} / \mathrm{m}^{2}$ at the external side of the wall, and it decreased to $30 \mathrm{~W} / \mathrm{m}^{2}$ at $23 \mathrm{~h}$; then, it gradually diminished towards the inside with a value of $2.5 \mathrm{~W} / \mathrm{m}^{2}$ for the air gap and approximatively $4 \mathrm{~W} / \mathrm{m}^{2}$ for the other insulators.

Figure 15 shows the heat flux as a function of the thickness and insulators at $t=12 \mathrm{~h}$. We note that there is no difference between the profiles of the four insulators at the external layer of brick. However, at the two other layers, the heat flux profile is almost constant and reaches a value of $5 \mathrm{~W} / \mathrm{m}^{2}$ for the glass wool, hemp wool, rock wool, and polystyrene while it is twice lower for the air gap with a value of $2.5 \mathrm{~W} / \mathrm{m}^{2}$.

3.2.2. Summer Period. Figure 16 presents the temperature's variation for the summer period from August first to $8^{\text {th }}$, 2019 , at the midheight of the envelope, which is consisting a double-layered hollow clay brick and different thermal insulators.

The temperature at the external side of the wall $T_{4}$ reaches $58^{\circ} \mathrm{C}$ during the summer period considering the solar radiation. The thermal resistance is particularly low if glass wool, rock wool, polystyrene, and hemp wool are used as insulators compared to the air gap. Indeed, the temperature at the external side of the glass wool, hemp wool, rock wool, and polystyrene $T_{3}$ balances between $29^{\circ} \mathrm{C}$ and $51^{\circ} \mathrm{C}$, and at its internal sides, $T_{2}$ varies between $27^{\circ} \mathrm{C}$ and $30^{\circ} \mathrm{C}$ (Table 4) which shows a heat reduction of $41.18 \%$, while the temperature at the external side of the air gap $T_{3}$ waves from $30^{\circ} \mathrm{C}$ to $52^{\circ} \mathrm{C}$ and its internal side $T_{2}$ varies from $26^{\circ} \mathrm{C}$ to $28^{\circ} \mathrm{C}$. Thus, the use of air gap in summer helps to reduce heat with a rate of $46.16 \%$ and reaches particularly a constant value $T_{1}$ of $25^{\circ} \mathrm{C}$ on the inside of the wall.

Figure 17 shows the heat flux as a function of the wall thickness of the different thermal insulations used (air gap, glass wool, hemp wool, rock wool, and polystyrene) at four moments per day $(7 \mathrm{~h}, 12 \mathrm{~h}, 19 \mathrm{~h}$, and $23 \mathrm{~h}$ ).

The recorded flux is maximal at $12 \mathrm{~h}$ and reaches a value of $115 \mathrm{~W} / \mathrm{m}^{2}$ at the external side of the wall, minimal at $7 \mathrm{~h}$, while at $23 \mathrm{~h}$, it reaches a value of $65 \mathrm{~W} / \mathrm{m}^{2}$ for the wall containing the air gap and a value of $60 \mathrm{~W} / \mathrm{m}^{2}$ for the other insulators. Then, the flux decreases slightly towards the interior of the wall with a value of $3 \mathrm{~W} / \mathrm{m}^{2}$ for the air gap and $5 \mathrm{~W} / \mathrm{m}^{2}$ for the other thermal insulators.

At $19 \mathrm{~h}$, the heat flux has the same profile as at $23 \mathrm{~h}$ with a gap of $3 \mathrm{~W} / \mathrm{m}^{2}$. Moreover, the heat flux decreases linearly in the external layer of the brick but with different values depending on the four moments of the day. At $7 \mathrm{~h}$, the heat flux is becoming almost constant with a value of $2 \mathrm{~W} / \mathrm{m}^{2}$.

Figure 18 represents the heat flux as a function of wall thickness and thermal insulation's type at $t=12 \mathrm{~h}$. We note that the profiles of the five insulators are similar at the external layer of brick; then, it decreases to the wall's internal side with different values, $2.5 \mathrm{~W} / \mathrm{m}^{2}$ for the air gap and $5 \mathrm{~W} / \mathrm{m}^{2}$ for the other insulators. 

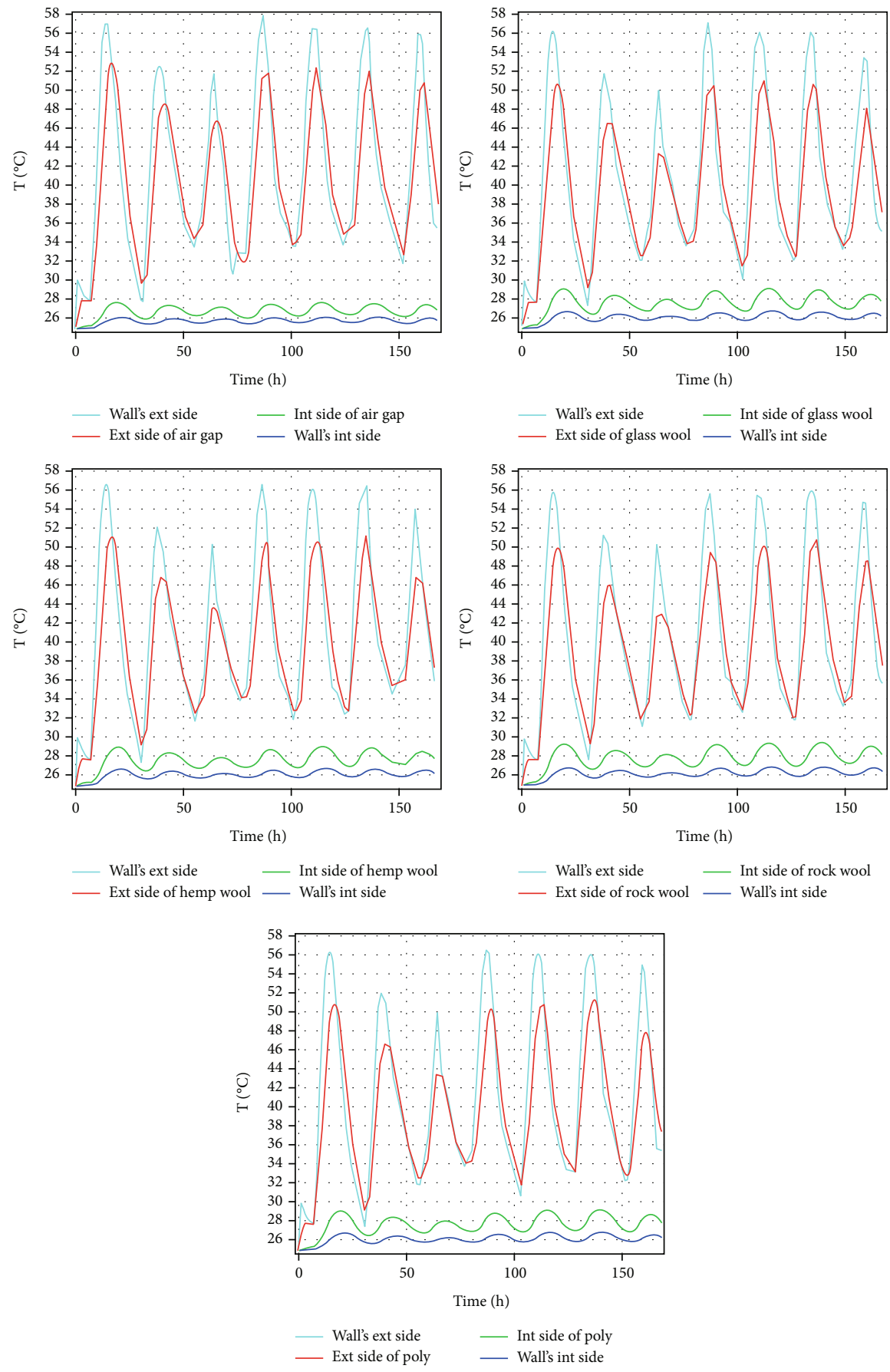

FIgURE 16: Temperature variation profiles of different sides of the wall and insulators during a summer period.

TABLE 4: Side's temperatures for the five insulations in the summer period.

\begin{tabular}{|c|c|c|c|c|c|c|c|c|}
\hline \multirow[t]{3}{*}{ Insulators } & \multicolumn{8}{|c|}{ Temperature $\left({ }^{\circ} \mathrm{C}\right)$} \\
\hline & \multicolumn{2}{|c|}{$T_{1}$} & \multicolumn{2}{|c|}{$T_{2}$} & \multicolumn{2}{|c|}{$T_{3}$} & \multicolumn{2}{|c|}{$T_{4}$} \\
\hline & Min & Max & Min & Max & Min & Max & Min & $\operatorname{Max}$ \\
\hline Air gap & 25 & 26 & 26 & 28 & 30 & 52 & 28 & 58 \\
\hline Glass wool & 26 & 27 & 27 & 30 & 29 & 51 & 28 & 58 \\
\hline Hemp wool & 26 & 27 & 27 & 30 & 29 & 51 & 28 & 58 \\
\hline Rock wool & 26 & 27 & 27 & 30 & 29 & 51 & 28 & 58 \\
\hline Polystyrene & 26 & 27 & 27 & 30 & 29 & 51 & 28 & 58 \\
\hline
\end{tabular}



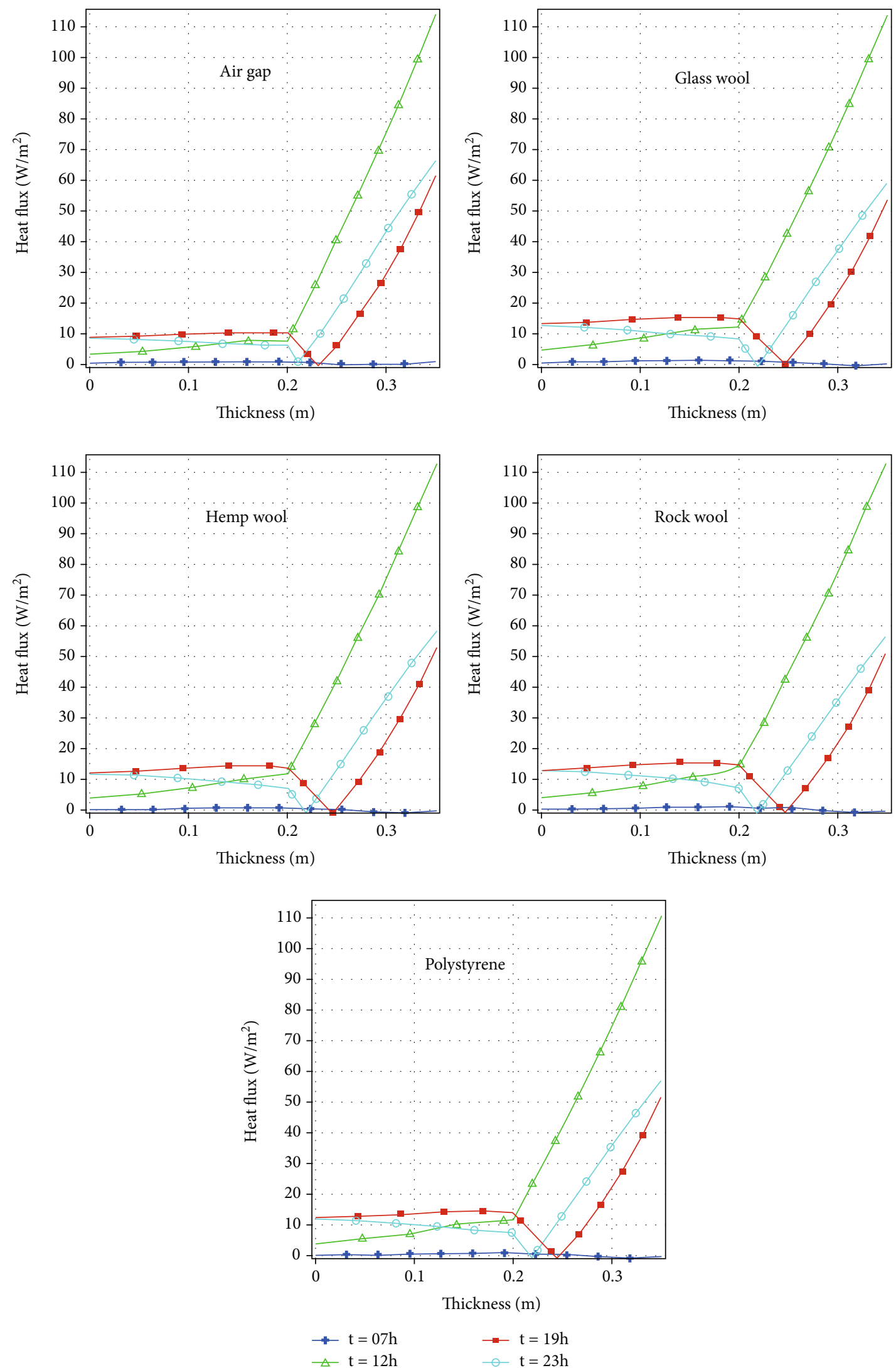

FigURE 17: Heat flux as a function of the wall thickness and insulators at different times of the day during the summer period. 


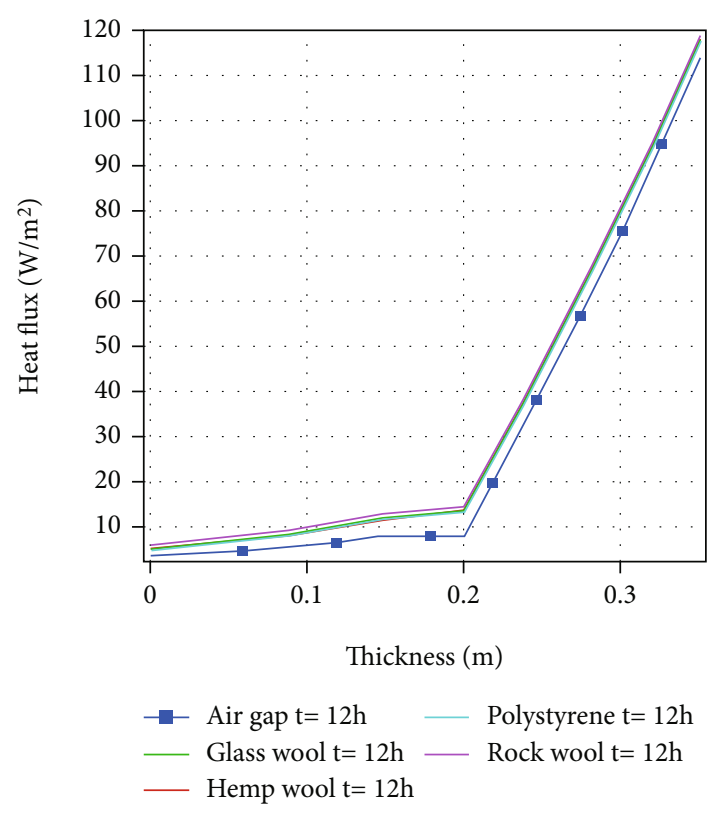

FIgURE 18: Heat flux as a function of the wall thickness and thermal insulation's type at $t=12 \mathrm{~h}$ during a summer period.

\section{Conclusions}

In this study, we have studied the effect of thermal insulation by air gap, hemp wool, glass wool, rock wool, and extruded polystyrene, plus the impact of their thicknesses $(5 \mathrm{~cm}$, $10 \mathrm{~cm}$, and $15 \mathrm{~cm}$ ) on heat transfer through an administrative building's envelope located in Errachidia City, under different climatic conditions during winter and summer periods.

The results show for stationary and transitional regimes, during the summer and the winter periods, in a semidesert climate of Errachidia City which is characterized by a significant sunshine. The thermal insulation by air gap is more efficient compared to the other thermal insulators under study; it acts as a heat absorber during the summer. While in winter, the air gap blocks heat towards the exit. Consequently, it ensures simultaneously the thermal comfort of the occupants and energy savings and reduces the materials' costs.

\section{Data Availability}

The datasets generated during and/or analyzed during the current study are available from the corresponding authors on reasonable request.

\section{Conflicts of Interest}

No potential conflict of interest was reported by the authors.

\section{Acknowledgments}

I would like to express my special thanks to all the coauthors for their enriching contribution.

\section{References}

[1] L. Lairgi, A. Daya, R. Elotmani, and M. Touzani, "Contribution to the study of the energy needs for a building in the city of Errachidia influence of orientation and local materials," Key Engineering Materials, vol. 820, pp. 18-28, 2019.

[2] M. Boukendil, A. Abdelbaki, and Z. Zrikem, "Detailed numerical simulation of coupled heat transfer by conduction, natural convection and radiation through double honeycomb walls," Building Simulation, vol. 5, no. 4, pp. 337-344, 2012.

[3] Ö. Kaşka and R. Yumrutaş, "Comparison of experimental and theoretical results for the transient heat flow through multilayer walls and flat roofs," Energy, vol. 33, no. 12, pp. 1816$1823,2008$.

[4] A. Louanate, R. El Otmani, K. Kandoussi, M. Boutaous, and D. Abdelmajid, "Energy saving potential of phase change materials-enhanced building envelope considering the six Moroccan climate zones," Journal of Building Physics, 2021.

[5] R. Sharston and S. Murray, "The combined effects of thermal mass and insulation on energy performance in concrete office buildings," Advances in Building Energy Research, vol. 14, no. 3, pp. 322-337, 2020.

[6] A. Missoum, M. Elmir, M. Bouanini, and B. Draoui, "Numerical simulation of heat transfer through the building facades of buildings located in the city of Bechar," International Journal of Multiphysics, vol. 10, no. 4, pp. 441-450, 2016.

[7] A. Louanate, R. El Otmani, K. Kandoussi, and M. Boutaous, "Dynamic modeling and performance assessment of single and double phase change material layer-integrated buildings in Mediterranean climate zone," Journal of Building Physics, vol. 44, no. 5, pp. 461-478, 2021.

[8] H. Asan, "Numerical computation of time lags and decrement factors for different building materials," Building and Environment, vol. 41, no. 5, pp. 615-620, 2006.

[9] H. Asan, "Effects of wall's insulation thickness and position on time lag and decrement factor," Energy and Buildings, vol. 28, no. 3, pp. 299-305, 1998.

[10] B. Jamal, M. Boukendil, A. Abdelbaki, and Z. Zrikem, "Numerical simulation of coupled heat transfer through double solid walls separated by an air layer," International Journal of Thermal Sciences, vol. 156, article 106461, 2020.

[11] P. Talukdar, S. O. Olutmayin, O. F. Osanyintola, and C. J. Simonson, "An experimental data set for benchmarking 1-D, transient heat and moisture transfer models of hygroscopic building materials. Part I: experimental facility and material property data," International Journal of Heat and Mass Transfer, vol. 50, no. 23-24, pp. 4527-4539, 2007.

[12] S. A. Al-Sanea, M. F. Zedan, and S. A. Al-Ajlan, "Effect of electricity tariff on the optimum insulation-thickness in building walls as determined by a dynamic heat-transfer model," Applied Energy, vol. 82, no. 4, pp. 313-330, 2005.

[13] Y. Tamene, S. Abboudi, and C. Bougriou, "Numerical and economical study of thermal insulation in multi-layer wall exposed to real climatic conditions," Athens Journal of Technology Engineering, vol. 1, no. 2, pp. 137-148, 2014.

[14] N. Mendes and P. C. Philippi, "A method for predicting heat and moisture transfer through multilayered walls based on temperature and moisture content gradients," International Journal of Heat and Mass Transfer, vol. 48, no. 1, pp. 37-51, 2005.

[15] N. Mendes, P. C. Philippi, and R. Lamberts, "A new mathematical method to solve highly coupled equations of heat 
and mass transfer in porous media," International Journal of Heat and Mass Transfer, vol. 45, no. 3, pp. 509-518, 2002.

[16] D. Kolokotsa, V. Vagias, L. Fytraki, and K. Oungrinis, "Energy analysis of zero energy schools: the case study of child's asylum in Greece," Advances in Building Energy Research, vol. 13, no. 2, pp. 193-204, 2019.

[17] Q. Darakdjian, S. Billé, and C. Inard, "Data mining of building performance simulations comprising occupant behaviour modelling," Advances in Building Energy Research, vol. 13, no. 2, pp. 157-173, 2019.

[18] J. Baliti, M. Hssikou, and M. Alaoui, "Numerical simulation of heat transfer in a micro-cavity," Canadian Journal of Physics, vol. 95, no. 1, pp. 85-94, 2017.

[19] A. Alami Merrouni, A. I. Amrani, H. A. Lahoussine Ouali, M. A. Moussaoui, and A. Mezrhab, "Numerical simulation of linear Fresnel solar power plants performance under Moroccan climate," Journal of Materials and Environmental Science, vol. 8, no. 12, pp. 4226-4233, 2017.

[20] L. Boukhattem, H. Hamdi, and D. R. Rousse, "Numerical simulation of heat transfers in a room in the presence of a thin horizontal heated plate," Energy Procedia, vol. 42, pp. 549556, 2013.

[21] M. Ahmed and A. Radwan, "Performance evaluation of new modified low-concentrator polycrystalline silicon photovoltaic/thermal systems," Energy Conversion and Management, vol. 149, pp. 593-607, 2017.

[22] M. W. Nansteel and R. Greif, "Natural convection in undivided and partially divided rectangular enclosures," Journal of Heat Transfer, vol. 103, no. 4, pp. 623-629, 1981.

[23] J. Yu, C. Yang, and L. Tian, "Low-energy envelope design of residential building in hot summer and cold winter zone in China," Energy and Buildings, vol. 40, no. 8, pp. 1536-1546, 2008.

[24] S. Perumal, S. Rajendrian, V. Venkatraman, D. Sundaresan, and L. Pandiyan, "Experimental study about thermal resistance of windows with air gap between two glasses used in single houses," Thermal Science, vol. 24, no. 1 Part B, pp. 515-518, 2020. 